\title{
Comprehensive Comparison Between Geriatric and Nongeriatric Patients With Trauma
}

\author{
Pei-Chen Lin \\ Taipei Medical University \\ Nan-Chun Wu \\ Chi Mei Medical Center \\ Hsiu-Chen Su \\ Chi Mei Medical Center \\ Chien-Chin Hsu \\ Chi Mei Medical Center

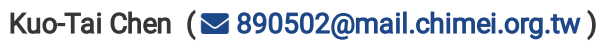 \\ Chi Mei Medical Center
}

\section{Research Article}

Keywords: trauma, geriatric, outcome, incidence, elderly

Posted Date: April 19th, 2021

DOI: https://doi.org/10.21203/rs.3.rs-403103/v1

License: (c) This work is licensed under a Creative Commons Attribution 4.0 International License. Read Full License

Version of Record: A version of this preprint was published at Medicine on February 18th, 2022. See the published version at https://doi.org/10.1097/MD.0000000000028913. 


\section{Abstract}

Purpose:

The incidence of geriatric trauma is increasing due to the growing elderly population. Healthcare providers require a global perspective to differentiate critical factors that might alter patients' prognosis.

\section{Methods:}

We retrospectively reviewed all adult patients admitted to a trauma center during a 4-year period. We identified 655 adult trauma patients aged from 18 to 64 (nongeriatric group) and 273 trauma patients $\geq 65$ years (geriatric group). Clinical data were collected and compared between the two groups.

\section{Results:}

The geriatric group had a higher incidence of trauma and higher Injury Severity Scores than did the nongeriatric group. Fewer geriatric patients underwent surgical treatment (all patients: geriatric vs. nongeriatric: $65.9 \%$ vs. $70.7 \%$; patients with severe trauma: geriatric vs. nongeriatric: $27.6 \%$ vs. $44.5 \%$ ). Regarding prognosis, the geriatric group exhibited higher mortality rate and less need for long-term care (geriatric vs. nongeriatric: mortality: $5.5 \%$ vs. $1.8 \%$; long-term care: $2.2 \%$ vs. $5.0 \%)$.

\section{Conclusion:}

We observed that geriatric patients had higher trauma incidence and higher trauma mortality rate. Aging is a definite predictor of poor outcomes for trauma patients. Limited physiological reserves and preference for less aggressive treatment might be the main reasons for poor outcomes in elderly individuals.

\section{Background}

Geriatric trauma is becoming a major problem because geriatric citizens are projected to constitute approximately one-fifth of the world's population by 2050 and because optimal management strategies for geriatric patients with trauma remain to be determined[1,2]. Elderly patients usually exhibit diverse comorbidities, receive polypharmacy, and have limited physiological reserves, implying a relatively high risk of death and severe disability[3]. A Spanish survey demonstrated that patients aged $>65$ years accounted for up to $20 \%$ of patients admitted to intensive care units[4]. Several studies have focused on the differences between geriatric and nongeriatric patients with trauma. The scopes of such studies included emergency medical services, triage, trauma team activation, trauma mechanisms, thoracic injury, traumatic brain injury, and laboratory tests, in addition to the effectiveness of various trauma scores in a geriatric population and in-hospital management of geriatric patients with trauma[1,5-16].

However, the limitation of these studies is that they have only partially addressed geriatric trauma. Healthcare providers require a global perspective to differentiate major factors that might impact a patient's prognosis and the relationship between these factors. Accordingly, we conducted this study to collect comprehensive data, including prehospital records and the entire hospital courses, regarding patients with trauma admitted to a trauma center in southern Taiwan. This study can provide exhaustive information regarding the differences in clinical details between geriatric and nongeriatric patients with trauma.

\section{Methods}

\section{Study Patients and Data Collection}

We retrospectively reviewed all patients admitted to the adult wards of a trauma center in southern Taiwan between July 1 and October 31,2016 . Of a total of 8297 patients, we excluded 7293 patients without trauma and 76 patients with trauma who were aged $<18$ years. The remaining 928 patients constituted our study cohort, of whom 655 patients were aged $<65$ years (nongeriatric group) and 273 patients were $\geq 65$ years (geriatric group), respectively. Trauma incidence was estimated using the census data in the same year. We stratified the geriatric group according to a 10-year interval to observe the trend of interval changes.

We collected the following data: demographic characteristics (age, sex, and Charlson comorbidity index), prehospital presentation (location of injury, mechanism of injury, and time of transportation from the site of injury to the hospital), clinical presentation at emergency department (ED) [vital signs, shock index [heart rate/systolic arterial pressure], triage (Taiwan Triage and Acuity Scale, TTAS)[17], Glasgow Coma Scale, interventions performed at ED, time from the ED to the ward, and time from the ED to the operating room, various trauma scores (Abbreviated Injury Scale score, Injury Severity Score, New Injury Severity Score, Revised Trauma Score, and Trauma Injury Severity Score)], hospital course (need for surgery, need for intensive care, hospital length of stay, and intensive care unit length of stay), and prognosis (recovery, mortality, need for long-term care, acute transfer, and complications).

\section{Comparisons between Geriatric and Nongeriatric Group}

We compared the data between the geriatric and nongeriatric groups. Because most of the patients included in this study sustained mild injuries and may not represent the actual conditions of severely wounded patients, we conducted a subgroup analysis to address this concern; from all patients with trauma, we selected patients with severe trauma (defined as Injury Severity Score $>15$ ) and divided them into geriatric and nongeriatric groups. Subsequently, we compared the collected data regarding the aforementioned variables between these two groups of patients with severe trauma.

Moreover, we collected the data of every patient who had undergone surgery during admission and analyzed the outcomes, Injury Severity Scores, and need for intensive care and life-saving procedures. The Institutional Review Board of Human Research, Chi-Mei Medical Center granted this study exemption from 
approval because the researchers used deidentified data. The study was conducted in accordance with the Declaration of Helsinki.

\section{Statistical Analysis}

Statistical analyses were performed using SPSS 15 (SPSS, Inc., Chicago, IL, USA). We employed the chi-square test and Student's t test to evaluate differences in dichotomous and continuous variables, respectively, between the various groups. Continuous data are presented as mean \pm standard deviation. Because the time period from injury to the ED, from the ED to the ward, and from the ED to the operating room involved a relatively high number of outliers, we compared these data between the groups by using the Mann-Whitney $\mathrm{U}$ test; these data are also presented as median and interquartile range. Overall, statistical significance was set at a $p$ value of $<0.05$.

\section{Results}

\section{All Patients with Trauma}

Figure 1 showed the study profile. In 2016, the number of citizens living in the city of study hospital was 1,886,033[18]. We thus used citizens as the analysis unit to estimate the incidence of trauma in various age intervals. Of all hospitalized patients, the geriatric group had a higher incidence of trauma than did the nongeriatric group ( $1.1 / 1000$ vs. $0.5 / 1000)$. Additionally, we observed that the incidence of trauma increased with age (65-74 years vs. $75-84$ years vs. $\geq 85$ years: $1.0 / 1000$ vs. $1.4 / 1000$ vs. 2.9/1000). This incidence of trauma is illustrated in Figure 2.

Table 1 presents a comparison of all geriatric and nongeriatric patients with trauma in terms of demographic characteristics. Except for age, The geriatric and nongeriatric groups exhibited similar sex distributions and proportions of patients with a Charlson comorbidity index of $>0$. Regarding prehospital conditions (location of injury, mechanism of injury, and time of transportation from the site of injury to the hospital), we observed that the geriatric group was associated with a longer time of transportation from the site of injury to the ED compared with the nongeriatric group. Concerning vital signs and triage in the ED, we found no differences between the geriatric and nongeriatric groups, except for respiratory rate, which was lower in the geriatric group.

The geriatric and nongeriatric groups also exhibited similar distributions with respect to region of injury. The geriatric group had a higher Injury Severity Score and New Injury Severity Score than did the nongeriatric group. However, the geriatric and nongeriatric groups exhibited similar Revised Trauma Scores and Trauma Injury Severity Scores. The average values of all laboratory test parameters were within normal limits for the geriatric and nongeriatric groups, except for the average white blood cell count, which was elevated in these two groups. We observed significant differences in potassium and glucose levels between the geriatric and nongeriatric groups. Other laboratory test parameters were similar between the two groups.

Fewer geriatric patients underwent surgery during their hospitalizations than nongeriatric patients $(65.9 \%$ vs. $70.7 \%, p=0.000)$. Other management procedures and hospital courses were similar between the geriatric and nongeriatric groups.

\section{Patients with Severe Trauma (Injury Severity Score > 15)}

Table 2 presents a comparison of geriatric and nongeriatric patients with severe trauma in terms of demographic characteristics. This subgroup analysis included 58 and 128 geriatric and nongeriatric patients, respectively. Except for age, The geriatric and nongeriatric groups exhibited similar sex distributions and percentages of patients with a Charlson comorbidity index of $>0$, we discovered that the geriatric group had a higher proportion of patients transferred from other hospitals than did the nongeriatric group.

We noted no differences between the geriatric and nongeriatric groups with respect to vital signs and triage in the ED except for respiratory rate, which was lower in the geriatric group.

Furthermore, the geriatric and nongeriatric groups exhibited similar distributions with respect to region of injury. The geriatric group had higher Injury Severity Score and New Injury Severity Score and lower Trauma Injury Severity Score than did the nongeriatric group. However, the two groups exhibited similar Revised Trauma Scores.

The values of three laboratory test parameters differed significantly between the geriatric and nongeriatric groups. Specifically, the geriatric group had higher levels of hemoglobin, creatinine, and alanine transaminase.

Fewer geriatric patients underwent surgery than did nongeriatric patients $(27.6 \%$ vs. $44.5 \%, p=0.028)$. Other managements and hospital courses were similar between the geriatric and nongeriatric groups.

\section{Prognosis}

Figure 3 summarizes the prognosis of all patients. We observed an increase in mortality with age (all patients with trauma: $18-64$ years vs. $65-74$ years vs. $75-84$ years vs. $\geq 85$ years: $1.8 \%$ vs. $4.8 \%$ vs. $5.0 \%$ vs. $8.3 \%$; patients with severe trauma: $18-64$ years vs. $65-74$ years vs. $75-84$ years vs. $\geq 85$ years: $9.4 \%$ vs. $18.5 \%$ vs. $22.2 \%$ vs. $33.3 \%$ ). Figure 3 illustrates the observed incidence and mortality in different age groups in our study populations.

Comparing the geriatric and nongeriatric groups, the geriatric group had a higher mortality rate and less need for long-term care (mortality: $5.5 \%$ vs. $1.8 \%$; longterm care: $2.2 \%$ vs. $5.0 \%$; recovery: $92.3 \%$ vs. $93.0 \%$; acute transfer: $0.0 \%$ vs. $0.2 \%, p=0.005$ ). The difference in mortality between the geriatric and nongeriatric 
group was greater in severe trauma $(22.4 \%$ vs. $9.4 \%, p=0.046)$. Regarding complication rates, geriatric patients and nongeriatric patients in this study showed similar complication rates.

\section{Patients Who Underwent Surgery}

We discovered that the geriatric trauma patients had a lower surgical rate compared to nongeriatric patients; such difference was greater in severe trauma cases and might contributed to the prognostic differences between the two groups. Therefore, we selected all patients who had undergone surgery and divided them into geriatric (184 patients) and nongeriatric (465 patients) groups to compare their trauma severity, resource requirements, and prognosis (Table 3 ). The geriatric group had a lower percentage of patients with multiple trauma (defined as patients with an Injury Severity Score of $>2$ in two regions) than did the nongeriatric group; however, the difference did not reach statistical significance (geriatric group vs. nongeriatric group: $3.8 \%$ vs. $7.5 \%, p=0.082$ ). Furthermore, the geriatric group included fewer patients who sustained severe injuries in the head and neck regions (defined as an Abbreviated Injury Scale $>2$ in the head and neck regions) than did the nongeriatric group ( $20.0 \%$ vs. $42.3 \%, p=0.000)$. The need for intensive care and the need for life-saving procedures were comparable between the geriatric and nongeriatric groups; nevertheless, the geriatric group had higher proportions of patients who died, required long-term care, and had complications than did the nongeriatric group (mortality: $3.8 \%$ vs. $1.3 \%$; long-term care: $9.8 \%$ vs. $1.7 \%$; recovery: $85.9 \%$ vs. $95.9 \%, p=0.000$; complication: $3.8 \%$ vs. $3.2 \%, p=0.000)$.

\section{Discussion}

From the results, we found the incidence and mortality rate of trauma increased with age in geriatric group. Compared to the nongeriatric group, the geriatric group showed higher mortality rate, fewer patients underwent surgical treatment, higher trauma scores, a longer time of transportation from the site of injury to the ED, more requirements for inter-hospital transfer, and clinically insignificant differences in vital signs and laboratory tests.

A survey in the United States for the period 2000-2011 revealed that the mean age of inpatients with trauma increased between 2000 and 2011[19]. The aging of the inpatient trauma population is a reflection of population aging in most countries worldwide. The findings of this study support that the incidence of inpatient trauma increased with age. Moreover, we observed that an increase in the incidence of trauma was accompanied by an increase in mortality in geriatric patients. Aging predisposes the geriatric population to trauma and increases the risk of them requiring care.

In the prehospital settings, we discovered that more than $40 \%$ of geriatric patients with severe trauma were transferred from other hospitals. Chi-Mei Medical Center is a regional level I trauma center in southern Taiwan and usually takes over difficult patients as well as patients with severe trauma transferred from other hospitals. For transfer patients, the time from injury to the ED (i.e., ED at the receiving hospital) was usually longer because it included the time spent in the referring hospital. Therefore, we considered that the longer time from injury to ED in geriatric trauma patients was due to the higher percentage of patient transfer in the geriatric group.

Regarding triage, vital signs in ED, and laboratory test parameters, the geriatric and nongeriatric groups differed with respect to respiratory rate and potassium, glucose, hemoglobin, creatinine, and alanine transaminase levels. However, for most variables that differed significantly between the groups, the data were within or near normal limits. Such slight differences seldom change the decision making of trauma surgeons in patient management. Scholars commonly assume that the vital signs of geriatric patients might be altered by medications or that the laboratory parameters of such patients might be within abnormal limits; however, we did not observe meaningful differences in triage, vital signs in ED, or laboratory test parameters between the geriatric and nongeriatric patients.

Regarding various factors from prehospital settings to hospital management, we observed that the differences between the geriatric and nongeriatric groups were negligible. Aging is a definite predictor of poor outcomes for patients with trauma. For all patients with trauma and for patients with severe trauma, we noted that the geriatric group had a higher mortality rate than the nongeriatric group. Three possible explanations for these findings are outlined as follows: (1) Under the same mechanism of injury, geriatric patients incurred more severe trauma than younger patients. (2) For a certain injury severity level, geriatric trauma patients had higher mortality rates than younger patients because of their existing comorbidities and limited physiological reserves. (3) Finally, geriatric patients undergo less invasive interventions during hospitalization than their younger counterparts.

The first two explanations are consistent with the finding of Evans et al., who revealed that even minor trauma, such as ground-level falls, could result in severe injury and sequelae in geriatric patients[20]. Frailty, sarcopenia, and polypharmacy (especially anticoagulants and antiplatelets) are conducive to poor outcomes in elderly patients[5].

With recent advancements in palliative care services, increasing numbers of patients and their families opt for palliative care over aggressive treatment for severely ill patients[21]. Older individuals exhibit poorer outcomes than their younger counterparts, as indicated by their higher in-hospital mortality rates, accelerated mortality following discharge, and-for those who survive-worse functional outcome at 6 months[22]. Hence, increasing numbers of geriatric patients and their families prefer tailoring the goals of treatment. This approach reduces the burden induced by long-term care and improves the quality of life of patients. We also observed that fewer patients in the geriatric group underwent surgery than those in the nongeriatric group. Among patients who underwent surgery, the geriatric group had a lower percentage of patients with multiple trauma or severe head and neck injuries, because polytrauma and severe head injury are often resulted in long-term disability of the trauma victims[2]. These findings indicate that elderly patients are prone to select noninvasive management, particularly the severely injured patients or patients with injuries that might result in long-term disability. Thus, the preference of older individuals to avoid aggressive treatment might also contributes to their higher mortality and less need for long-term care. 


\section{Limitations}

This study has several limitations. First, the data were derived from a single trauma center, which may not be representative of the actual geriatric trauma population. In addition, the estimated incidence of trauma may be inaccurate. Nevertheless, the study hospital is a regional trauma center and has the most ED visits (120,000 annually) among all hospitals in the region. We believe that the collected data could portray the actual situation of geriatric trauma in Taiwan. Second, because all the data were obtained from retrospective chart reviews, the preinjury condition of each patient was not recorded precisely. Some elderly individuals may had been referred from convalescent care centers before their admission. They would be sent back for long-term care even if the injury did not result in further disability. Therefore, the need for long-term care might be overestimated in this study. However, if the need for long-term care were reduced, the difference between the geriatric and nongeriatric groups would be more pronounced than that presented herein. Third, we did not perform followup assessments to verify the condition of each patient after discharge. Some patients might have recovered completely after undergoing care in convalescent care centers. We agree that this study only demonstrated the acute differences between the geriatric and nongeriatric populations following injury. Future studies are required to understand the long-term results of geriatric trauma.

\section{Conclusion}

We observed that an increase in the incidence of trauma was accompanied by an increase in mortality in geriatric patients. Under similar covariants from prehospital settings to hospital management, the geriatric patients incurred more severe injuries and had higher mortality rates than nongeriatric patients. Aging is definitely a predictor of poor outcomes for patients with trauma. Limited physiological reserves and the preference for less aggressive treatment could be the main reasons for poor outcomes in elderly individuals.

\section{Declarations}

Funding: No funding.

Conflicts of interest/Competing interests: The authors declare that they have no competing interests or competing interests.

Availability of data and material: Not applicable.

Code availability: Not applicable.

\section{Authors' contributions:}

Pei-Chen Lin: Acquisition of the data; drafting of the manuscript.

Nan-Chun Wu: Critical revision of the manuscript.

Hsiu-Chen Su: Acquisition and analysis of the data.

Chien-Chin Hsu: Analysis of the data.

Kuo-Tai Chen: Study design and approval of final manuscript

Ethics approval: This study was reviewed and approved by the Institutional Review Board of Human Research, Chi-Mei Medical Center.

Consent to participate: The Institutional Review Board of Human Research, Chi-Mei Medical Center approved the waive of patient's consent.

Consent for publication: The Institutional Review Board of Human Research, Chi-Mei Medical Center approved the waive of patient's consent.

\section{References}

1. Bonne S, Schuerer DJ. Trauma in the older adult: epidemiology and evolving geriatric trauma principles. Clin Geriatr Med. $2013 ; 29:$ 137-50.

2. Kozar RA, et al. Injury in the aged: Geriatric trauma care at the crossroads. J Trauma Acute Care Surg. 2015; 78: 1197-209.

3. Llompart-Pou JA, Pérez-Bárcena J, Chico-Fernández M, Sánchez-Casado M, Raurich JM. Severe trauma in the geriatric population. World J Crit Care Med. 2017; 6: 99-106.

4. Chico-Fernández M, et al. Epidemiology of severe trauma in Spain. Registry of trauma in the ICU (RETRAUCI). Pilot phase. Med Intensiva. 2016; 40: $327-$ 47.

5. Adams S, Holcomb JB. Geriatric trauma. Curr Opin Crit Care. 2015; 21: 520-6.

6. Calland JF, et al. Evaluation and management of geriatric trauma: an Eastern Association for the Surgery of Trauma practice management guideline. $\mathrm{J}$ Trauma Acute Care Surg. 2012; 73(Suppl 4): S345-50.

7. Bardes JM, Benjamin E, Schellenberg M, Inaba K, Demetriades D. Old Age with a Traumatic Mechanism of Injury Should Be a Trauma Team Activation Criterion. J Emerg Med. 2019; 57: 151-5.

8. Carpenter CR, Avidan MS, Wildes T, Stark S, Fowler SA, Lo AX. Predicting geriatric falls following an episode of emergency department care: a systematic review. Acad Emerg Med.2014; 21: 1069-82. 
9. Harrington DT, et al. Factors associated with survival following blunt chest trauma in older patients: results from a large regional trauma cooperative. Arch Surg. 2010; 145: 432-7.

10. Stein DM, et al. Geriatric traumatic brain injury-What we know and what we don't. J Trauma Acute Care Surg. 2018; 85: 788-98.

11. Schreiber FS, Becker I, Deckert P, Elsbernd H, Isensee C. Malnutrition and Laboratory Markers in Geriatric Patients. A Comparison of Neurologic-psychiatric, Internal and Trauma Surgical Diseases. J Nutr Health Aging. 2016; 20: 458-61.

12. Hao Q, Sun X, Yang M, Dong B, Dong B, Wei Y. Prediction of mortality in Chinese very old people through the frailty index based on routine laboratory data. Sci Rep. 2019; 9: 221.

13. Madni TD, et al. A comparison of prognosis calculators for geriatric trauma: A Prognostic Assessment of Life and Limitations After Trauma in the Elderly consortium study. J Trauma Acute Care Surg. 2017; 83: 90-6.

14. Wong $\mathrm{TH}$, et al. Combining the new injury severity score with an anatomical polytrauma injury variable predicts mortality better than the new injury severity score and the injury severity score: a retrospective cohort study. Scand J Trauma Resusc Emerg Med. 2016; 24:25.

15. Mulvey HE, Haslam RD, Laytin AD, Diamond CA, Sims CA. Unplanned ICU Admission Is Associated With Worse Clinical Outcomes in Geriatric Trauma Patients. J Surg Res. 2020; 245: 13-21.

16. Maxwell CA, Miller RS, Dietrich MS, Mion LC, Minnick A. The aging of America: a comprehensive look at over 25,000 geriatric trauma admissions to United States hospitals. Am Surg. 2015; 81: 630-6.

17. Ministry of Health and Welfare. https://dep.mohw.gov.tw/DOMA/cp-2710-38118-106.html. Accessed October 31, 2020

18. Bureau of Civil Affairs of Taiwan City Government. https://w3fs.tainan.gov.tw/Download.ashx? u=LzAwMS9VcGxvYWQvMTYvcmVsZmlsZS850DQzLzgxNDUvMDE5MmZIY2UtZTQ1MS00Y2E3LWEWMmMtNmE30TkwNTA5YWNmLnBkZg\%3d\%3d\&n Accessed Jun 10, 2020.

19. DiMaggio C, , et al. Traumatic Injury in the United States: In-Patient Epidemiology 2000-2011. Injury. 2016; 47: 1393-403.

20. Evans D, Pester J, Vera L, Jeanmonod D, Jeanmonod R. Elderly fall patients triaged to the trauma bay: age, injury patterns, and mortality risk. Am J Emerg Med. 2015; 33: 1635-8.

21. Fried TR, Bradley EH, Towle VR. Valuing the outcomes of treatment: do patients and their caregivers agree? Arch Intern Med. 2003; 163: $2073-8$.

22. Fiorentino M, Hwang F, Pentakota SR, Livingston DH, Mosenthal AC. Palliative Care in Trauma: Not Just for the Dying. J Trauma Acute Care Surg. 2019; 87: $1156-63$.

\section{Tables}

TABLE 1. Comparison of the demographic characteristics between geriatric and nongeriatric groups for all adult patients with trauma 


\begin{tabular}{|c|c|c|c|}
\hline & $\begin{array}{l}\text { Geriatric } \\
\text { (All patients) }\end{array}$ & $\begin{array}{l}\text { Non-geriatric } \\
\text { (All patients) }\end{array}$ & $p$ \\
\hline Case number (\%) & $273(29.4 \%)$ & $655(70.6 \%)$ & \\
\hline Average age (year) & $76.3 \pm 8.0$ & $42.3 \pm 14.4$ & 0.000 \\
\hline Sex (Male) & $58.6 \%$ & $59.8 \%$ & 0.726 \\
\hline Charlson Comorbidity Index $>0$ & $28.6 \%$ & $25.5 \%$ & 0.333 \\
\hline \multicolumn{4}{|l|}{ Locations of injury } \\
\hline Street & $51.3 \%$ & $49.5 \%$ & \multirow[t]{5}{*}{0.492} \\
\hline Factory/ Farm/ Mine & $15.0 \%$ & $16.3 \%$ & \\
\hline Home & $12.8 \%$ & $15.3 \%$ & \\
\hline Public places & $5.1 \%$ & $3.1 \%$ & \\
\hline Others/ Unknown & $15.8 \%$ & $15.3 \%$ & \\
\hline \multicolumn{4}{|l|}{ Mechanisms of injury } \\
\hline Traffic accident & $49.5 \%$ & $49.5 \%$ & \multirow[t]{7}{*}{0.616} \\
\hline Fall & $29.7 \%$ & $33.4 \%$ & \\
\hline Crush & $7.7 \%$ & $9.2 \%$ & \\
\hline Burn/ Electricity & $5.9 \%$ & $4.6 \%$ & \\
\hline Penetrating injury & $4.8 \%$ & $3.5 \%$ & \\
\hline Asphyxia/ Drowning & $1.8 \%$ & $3.1 \%$ & \\
\hline Suicide & $0.7 \%$ & $0,8 \%$ & \\
\hline \multicolumn{4}{|l|}{ Prehospital transport } \\
\hline Transport by EMTs & $44.0 \%$ & $49.6 \%$ & \multirow[t]{3}{*}{0.107} \\
\hline Transport by themselves & $30.4 \%$ & $30.7 \%$ & \\
\hline Transfer from other hospital & $25.6 \%$ & $19.7 \%$ & \\
\hline \multirow[t]{2}{*}{ Time from injury to ED (median, interquartile range, min) } & 47.0 & 42.0 & \multirow[t]{2}{*}{0.005} \\
\hline & $(28.0-92.5)$ & $(25.0-80.0)$ & \\
\hline \multicolumn{4}{|l|}{ Vital signs at ED arrival } \\
\hline GCS & $14.3 \pm 2.3$ & $14.4 \pm 2.0$ & 0.196 \\
\hline $\mathrm{SAP}(\mathrm{mmHg})$ & $145.5 \pm 32.3$ & $144.9 \pm 32.9$ & 0.626 \\
\hline HR (beat/min) & $85.1 \pm 19.3$ & $86.4 \pm 19.2$ & 0.874 \\
\hline RR (respiration/min) & $17.3 \pm 2.9$ & $17.4 \pm 2.4$ & 0.022 \\
\hline Temperature $\left({ }^{\circ} \mathrm{C}\right)$ & $36.5 \pm 0.6$ & $36.5 \pm 0.7$ & 0.497 \\
\hline Shock Index (HR/SAP) & $0.6 \pm 0.2$ & $0.6 \pm 0.2$ & 0.318 \\
\hline \multicolumn{4}{|l|}{ Triage } \\
\hline Triage 1 & $7.7 \%$ & $7.8 \%$ & \multirow[t]{4}{*}{0.873} \\
\hline Triage 2 & $46.2 \%$ & $44.4 \%$ & \\
\hline Triage 3 & $45.8 \%$ & $47.6 \%$ & \\
\hline Triage 4 & $0.4 \%$ & $0.2 \%$ & \\
\hline \multicolumn{4}{|l|}{ Injury regions (Abbreviated Injury Scale > 2) } \\
\hline Head and neck & $22.7 \%$ & $20.9 \%$ & \multirow[t]{5}{*}{0.114} \\
\hline Face & $0.4 \%$ & $1.1 \%$ & \\
\hline Chest & $7.7 \%$ & $9.2 \%$ & \\
\hline Abdomen & $2.9 \%$ & $2.9 \%$ & \\
\hline Extremity & $23.8 \%$ & $27.8 \%$ & \\
\hline
\end{tabular}

Page $7 / 12$ 


\begin{tabular}{|c|c|c|c|}
\hline External & $1.8 \%$ & $0.3 \%$ & \\
\hline \multicolumn{4}{|l|}{ Severity of trauma } \\
\hline RTS & $7.6603 \pm 0.7588$ & $7.6868 \pm 0.6582$ & 0.294 \\
\hline ISS & $10.1 \pm 10.7$ & $9.2 \pm 7.6$ & 0.004 \\
\hline NISS & $12.7 \pm 12.6$ & $11.5 \pm 10.5$ & 0.013 \\
\hline TRISS & $0.9475 \pm 0.1440$ & $0.9571 \pm 0.1251$ & 0.087 \\
\hline \multicolumn{4}{|l|}{ Laboratory tests } \\
\hline White cell count (cell/uL) & $11800 \pm 4800$ & $11400 \pm 4600$ & 0.178 \\
\hline Hemoglobin $(g / L)$ & $13.6 \pm 2.0$ & $13.4 \pm 2.2$ & 0.090 \\
\hline Platelet (cell/uL) & $240700 \pm 67700$ & $242300 \pm 71100$ & 0.882 \\
\hline PT (INR) & $1.0 \pm 0.1$ & $1.0 \pm 0.1$ & 0.518 \\
\hline APTT (sec) & $25.9 \pm 3.9$ & $25.9 \pm 3.3$ & 0.803 \\
\hline Sodium (mmol/L) & $139.0 \pm 3.0$ & $139.5 \pm 2.5$ & 0.738 \\
\hline Potassium (mmol/L) & $3.8 \pm 0.3$ & $3.8 \pm 0.4$ & 0.034 \\
\hline Glucose $(\mathrm{g} / \mathrm{L})$ & $140.7 \pm 62.1$ & $135.1 \pm 48.5$ & 0.012 \\
\hline Creatinine (g/L) & $1.0 \pm 0.9$ & $1.0 \pm 0.7$ & 0.734 \\
\hline Alanine transaminase $(\mathrm{U} / \mathrm{L})$ & $32.0 \pm 56.6$ & $32.6 \pm 47.5$ & 0.975 \\
\hline \multicolumn{4}{|l|}{ Management and Hospital course } \\
\hline Surgery & $65.9 \%$ & $70.7 \%$ & 0.000 \\
\hline \multirow[t]{2}{*}{ Time from ED to ward (median, interquartile range, min) } & 40.5 & 40.5 & 0.380 \\
\hline & $(19.0-83.0)$ & $(20.0-75.5)$ & \\
\hline \multirow[t]{2}{*}{ Time from ED to surgery (median, interquartile range, $\min$ ) } & 323.5 & 347.0 & 0.808 \\
\hline & $(211.3-746.8)$ & $(199.0-671.0)$ & \\
\hline Hospital stay (day) & $9.3 \pm 10.9$ & $8.2 \pm 9.1$ & 0.457 \\
\hline ICU requirement & $22.3 \%$ & $16.9 \%$ & 0.054 \\
\hline ICU stay (day) & $8.1 \pm 12.6$ & $7.5 \pm 7.6$ & 0.115 \\
\hline
\end{tabular}

*SAP: systolic arterial pressure

THR: heart rate

‡RR: respiratory rate

RTS: revised trauma score

१ISS: Injury Severity Score

jNISS: New Injury Severity Score

**TRISS: Trauma Injury Severity Score

jjGCS: Glasgow Coma Scale

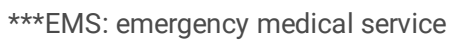

$\neq I C U$ : intensive care unit

TABLE 2. Comparison of demographic characteristics between geriatric and nongeriatric groups for patients with severe trauma (Injury Severity Score > 15) 


\begin{tabular}{|c|c|c|c|}
\hline & $\begin{array}{l}\text { Geriatric } \\
\text { (ISS>15 patients) }\end{array}$ & $\begin{array}{l}\text { Non-geriatric } \\
\text { (ISS>15 patients) }\end{array}$ & $p$ \\
\hline Case number (\%) & $58(31.2 \%)$ & $128(68.8 \%)$ & \\
\hline Average age (year) & $76.1 \pm 8.1$ & $41.2 \pm 14.5$ & 0.000 \\
\hline Sex (Male) & $65.5 \%$ & $65.5 \%$ & 0.989 \\
\hline Charlson Comorbidity Index > 0 & $34.5 \%$ & $29.7 \%$ & 0.513 \\
\hline \multicolumn{4}{|l|}{ Locations of injury } \\
\hline Street & $70.7 \%$ & $61.7 \%$ & \multirow[t]{5}{*}{0.561} \\
\hline Factory/ Farm/ Mine & $6.9 \%$ & $9.4 \%$ & \\
\hline Home & $12.1 \%$ & $10.2 \%$ & \\
\hline Public places & $3.4 \%$ & $3.9 \%$ & \\
\hline Others/ Unknown & $6.9 \%$ & $14.8 \%$ & \\
\hline \multicolumn{4}{|l|}{ Mechanisms of injury } \\
\hline Traffic accident & $69.0 \%$ & $57.0 \%$ & \multirow[t]{3}{*}{0.264} \\
\hline Fall & $24.1 \%$ & $30.5 \%$ & \\
\hline Others & $6.9 \%$ & $12.5 \%$ & \\
\hline \multicolumn{4}{|l|}{ Prehospital transport } \\
\hline Transport by EMTs & $51.7 \%$ & $57.0 \%$ & \multirow[t]{3}{*}{0.041} \\
\hline Transport by themselves & $6.9 \%$ & $17.2 \%$ & \\
\hline Transfer from other hospital & $41.4 \%$ & $25.8 \%$ & \\
\hline Time from injury to ED & 51.0 & 37.0 & 0.334 \\
\hline (median, interquartile range, min) & $(26.5-164.0)$ & $(25.0-112.0)$ & \\
\hline \multicolumn{4}{|l|}{ Vital signs at ED arrival } \\
\hline GCS & $12.2 \pm 4.3$ & $12.8 \pm 3.6$ & 0.219 \\
\hline SAP $(\mathrm{mmHg})$ & $146.7 \pm 40.4$ & $139.8 \pm 39.9$ & 0.891 \\
\hline HR (beat/min) & $87.9 \pm 24.3$ & $90.6 \pm 21.8$ & 0.611 \\
\hline RR (respiration/min) & $17.1 \pm 4.7$ & $17.5 \pm 3.5$ & 0.029 \\
\hline Temperature $\left({ }^{\circ} \mathrm{C}\right)$ & $36.5 \pm 0.6$ & $36.3 \pm 0.9$ & 0.783 \\
\hline Shock Index (HR/SAP) & $0.6 \pm 0.3$ & $0.7 \pm 0.3$ & 0.363 \\
\hline \multicolumn{4}{|l|}{ Triage } \\
\hline Triage 1 & $32.8 \%$ & $29.7 \%$ & \multirow[t]{3}{*}{0.395} \\
\hline Triage 2 & $55.2 \%$ & $50.0 \%$ & \\
\hline Triage 3 & $12.1 \%$ & $20.3 \%$ & \\
\hline \multicolumn{4}{|c|}{ Injury regions (Abbreviated Injury Scale > 2) } \\
\hline Head and neck & $77.6 \%$ & $81.3 \%$ & \multirow[t]{6}{*}{0.188} \\
\hline Face & $1.7 \%$ & $3.9 \%$ & \\
\hline Chest & $25.9 \%$ & $35.2 \%$ & \\
\hline Abdomen & $8.6 \%$ & $7.0 \%$ & \\
\hline Extremity & $8.6 \%$ & $16.4 \%$ & \\
\hline External & $3.4 \%$ & $0.0 \%$ & \\
\hline \multicolumn{4}{|l|}{ Severity of trauma } \\
\hline RTS & $7.0701 \pm 1.4942$ & $7.2367 \pm 1.2989$ & 0.211 \\
\hline ISS & $25.2 \pm 14.6$ & $21.8 \pm 7.0$ & 0.000 \\
\hline NISS & $32.2 \pm 12.9$ & $28.7 \pm 9.7$ & 0.036 \\
\hline
\end{tabular}

Page 9/12 


\begin{tabular}{|llll|}
\hline TRISS & $0.8094 \pm 0.2716$ & $0.8687 \pm 0.2168$ & 0.026 \\
\hline Laboratory tests & & & \\
\hline White cell count (cell/uL) & $13800 \pm 6400$ & $12500 \pm 5400$ & 0.069 \\
\hline Hemoglobin (g/L) & $13.2 \pm 1.8$ & $12.8 \pm 2.4$ & 0.043 \\
\hline Platelet (cell/uL) & $209800 \pm 67800$ & $233100 \pm 98000$ & 0.324 \\
\hline PT (INR) & $1.0 \pm 0.1$ & $1.0 \pm 0.2$ & 0.671 \\
\hline APTT (sec) & $27.2 \pm 7.9$ & $26.2 \pm 5.9$ & 0.239 \\
\hline Sodium (mmol/L) & $138.1 \pm 4.2$ & $139.5 \pm 2.7$ & 0.466 \\
\hline Potassium (mmol/L) & $3.7 \pm 0.4$ & $3.7 \pm 0.5$ & 0.290 \\
\hline Glucose (g/L) & $157.4 \pm 60.1$ & $153.7 \pm 54.1$ & 0.705 \\
\hline Creatinine (g/L) & $1.4 \pm 2.1$ & $1.0 \pm 0.5$ & 0.002 \\
\hline Alanine transaminase (U/L) & $56.4 \pm 126.5$ & $41.8 \pm 43.6$ & 0.028 \\
\hline Management and Hospital course & & & \\
\hline Surgery & $27.6 \%$ & $44.5 \%$ & 0.028 \\
\hline Time from ED to ward & 66.0 & 56.0 & 0.468 \\
\hline (median, interquartile range, min) & $(23.0-164.0)$ & $(21.0-168.0)$ & \\
\hline Time from ED to surgery & 408.5 & 355.0 & 0.805 \\
\hline (median, interquartile range, min) & $(109.5-1552.3)$ & $(94.5-1328.0)$ & \\
\hline Hospital stay (day) & $10.2 \pm 10.2$ & $8.9 \pm 10.5$ & 0.166 \\
\hline ICU requirement & $27.6 \%$ & $16.4 \%$ & \\
\hline ICU stay (day) & $6.8 \pm 9.6$ & $5.3 \pm 4.2$ & \\
\hline
\end{tabular}

*SAP: systolic arterial pressure

THR: heart rate

‡RR: respiratory rate

RTS: Revised Trauma Score

IISS: Injury Severity Score

jNISS: New Injury Severity Score

**TRISS: Trauma Injury Severity Score

jjGCS: Glasgow Coma Scale

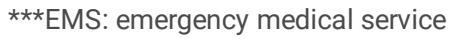

\#ICU: intensive care unit

TABLE 3. Data for all patients who underwent surgery. We observed that the geriatric group had a lower percentage of patients with multiple trauma than did the nongeriatric group, although the difference was nonsignificant. The geriatric group included fewer patients who sustained severe injuries in the head and neck regions (defined as Abbreviated Injury Scale of $>2$ for head and neck regions). Nevertheless, the geriatric group had a higher proportion of patients who died, required log-term care, and had complications 


\begin{tabular}{|llll|}
\hline & $\begin{array}{l}\text { Geriatric } \\
(\mathbf{1 8 4})\end{array}$ & $\begin{array}{l}\text { Non-geriatric } \\
\mathbf{( 4 6 5 )}\end{array}$ & $\boldsymbol{p}$ \\
\hline Multiple traumat & $3.8 \%$ & $7.5 \%$ & 0.082 \\
\hline Head and neck AIS¥ > 2 & $20.0 \%$ & $42.3 \%$ & $\mathbf{0 . 0 0 0}$ \\
\hline Requirement for intensive care & $11.4 \%$ & $11.2 \%$ & 0.933 \\
\hline Life-saving procedures* & $4.3 \%$ & $7.1 \%$ & 0.194 \\
\hline Died & $3.8 \%$ & $1.3 \%$ & $\mathbf{0 . 0 0 0}$ \\
\hline Long-term care & $9.8 \%$ & $1.7 \%$ & \\
\hline Recovery & $85.9 \%$ & $95.9 \%$ & \\
\hline Acute transfer & $0.5 \%$ & $1.1 \%$ & \\
\hline Complications & $3.8 \%$ & $3.2 \%$ & 0.000 \\
\hline
\end{tabular}

tPatients whose Injury Severity Score was $>2$ in two regions

$\ddagger$ Abbreviated Injury Scale

*Included emergent life-saving surgery and transarterial embolization.

\section{Figures}

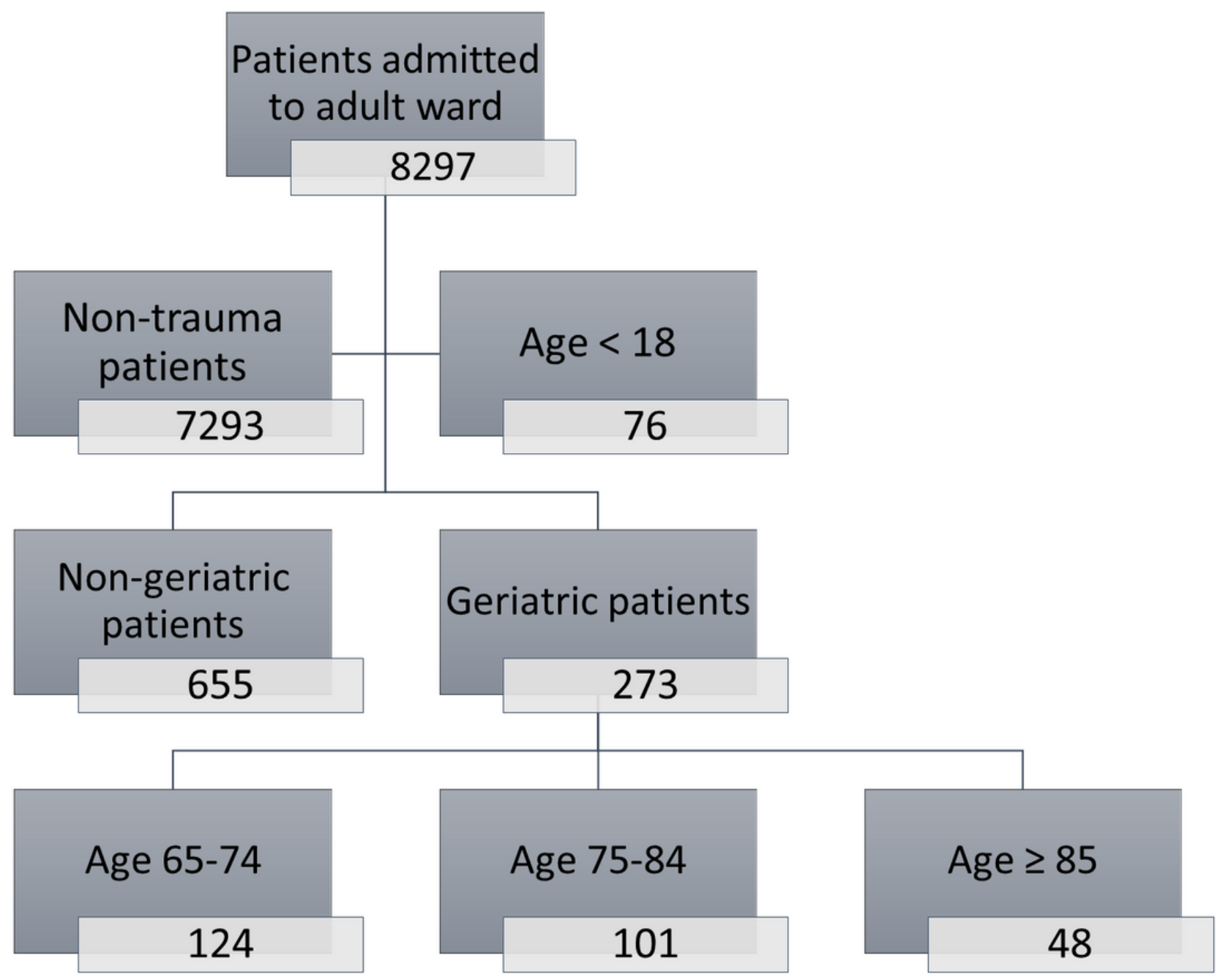

Figure 1

Study profile. The number in each box represents the number of cases for each group. 


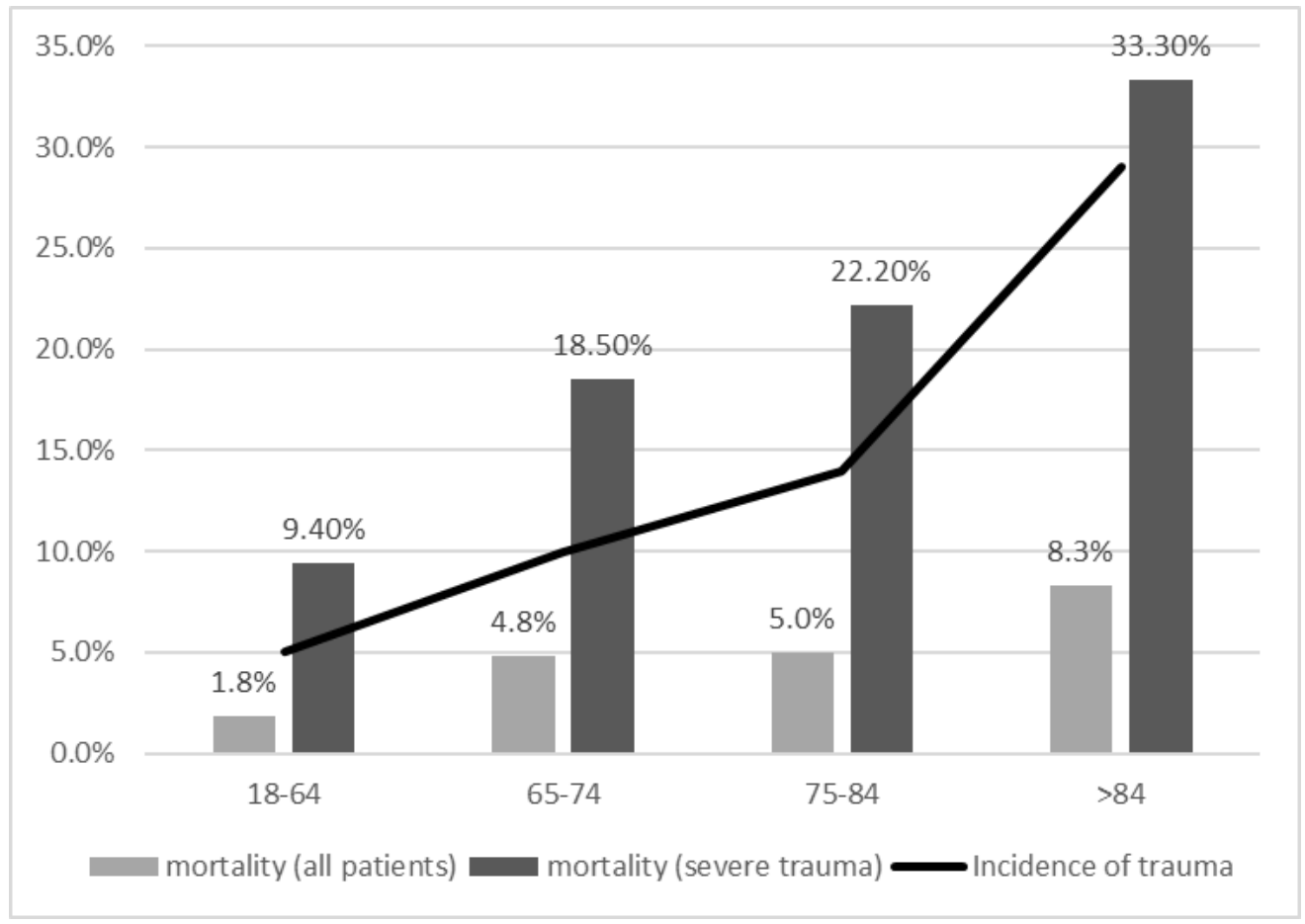

Figure 2

We discovered that the incidence of trauma increased with age (18-64 vs. $65-74$ vs. $75-84$ vs. $\geq 85$ years: $0.5 / 1000$ vs. $1.0 / 1000$ vs. $1.4 / 1000$ vs. $2.9 / 1000)$. Moreover, we observed an increase in mortality with age.

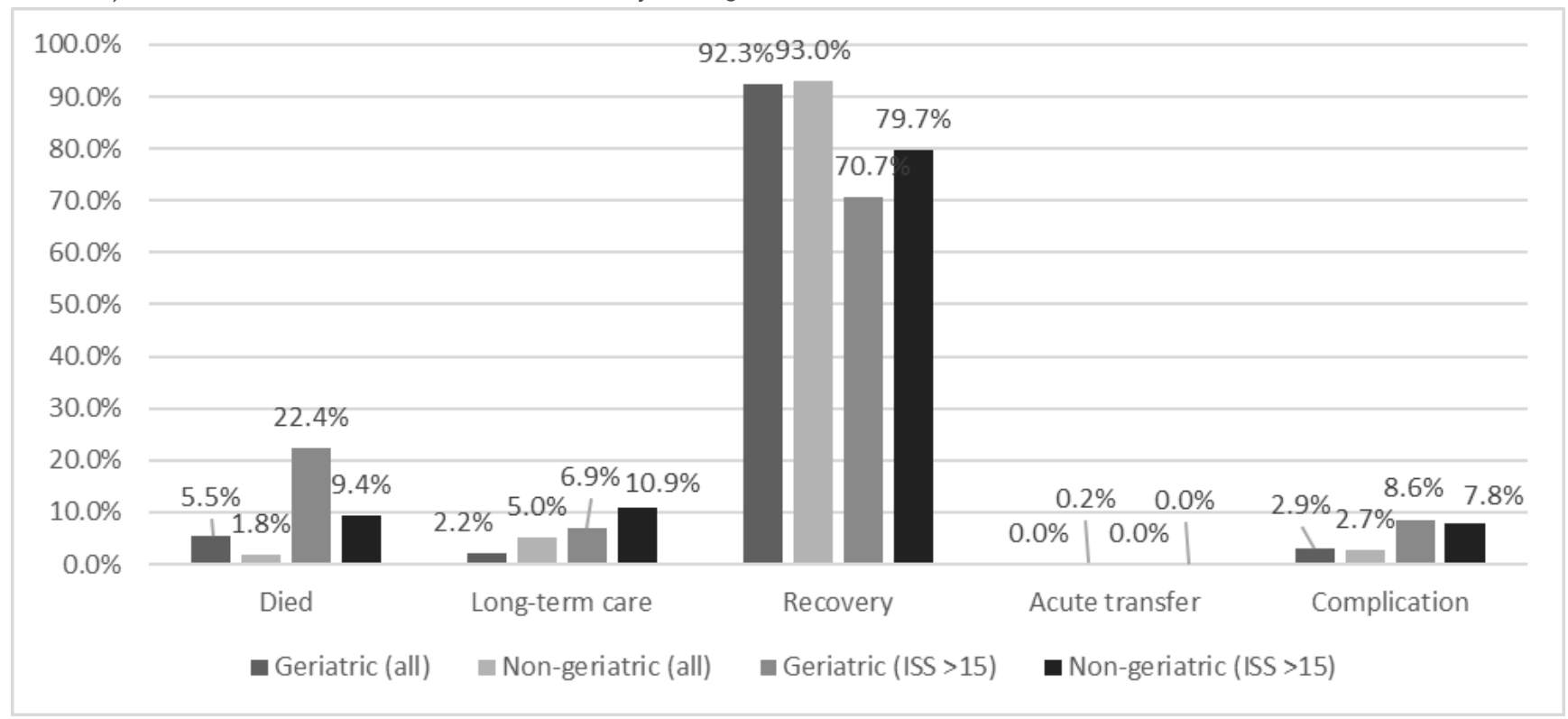

\section{Figure 3}

Regarding prognosis of the geriatric and nongeriatric groups, the geriatric group had a higher proportion of patients who died and lower proportion of patients who required long-term care. For all patients and for patients with severe trauma, the incidence rates of complications were comparable between geriatric and nongeriatric groups. 